\title{
Female Sexual Offending: A Neglected Criminal Justice Issue
}

\author{
James F. Anderson ${ }^{1}$, Tazinski Lee ${ }^{2}$, Adam H. Langsam ${ }^{3} \&$ Kelley Reinsmith-Jones ${ }^{4}$ \\ ${ }^{1}$ College of Arts and Sciences, Professor of Criminal Justice, East Carolina University, Greenville, NC, USA \\ ${ }^{2}$ College of Professional and Graduate Studies, Associate Professor of Criminal Justice, Grambling State University, \\ Grambling, LA, USA. \\ ${ }^{3}$ College of Liberal Arts, Professor of Sociology, Northeastern State University, Tahlequah, OK, USA, USA \\ ${ }^{4}$ College of Health and Human Performances, Associate Professor of Social Work, East Carolina University, Greenville, \\ $\mathrm{NC}$ \\ Correspondence: James F. Anderson, Professor, Department of Criminal Justice, East Carolina University, Greenville, \\ NC, USA.
}

Received: February 5, 2020

Accepted: March 2, 2020

Available online: March 6, 2020

doi:10.11114/ijsss.v8i3.4753

URL: https://doi.org/10.11114/ijsss.v8i3.4753

\begin{abstract}
Scholars, researchers, and law enforcement officers examining child sexual abuse cases are beginning to report that adolescent and adult females are responsible for a growing number of sexual offenses. This new revelation may reveal that justice officials and many in the lay public do not view the gravity of female and male sexual offending equally. This investigation reveals that female sex offending is more common than traditionally thought and is a neglected criminal justice issue. It also shows that until society recognizes that sex offending is not a gendered crime, more cases will escape the attention of the criminal justice system.
\end{abstract}

Keywords: female sexual offender, sexual abuse, hexamer typology, predator, Megan's law, civil commitments

\section{Introduction}

Critics often argue that there is little representative research on female sexual offenders (FSO) (Tozdan, Briken, \& Dekker, 2019). This may exist because all major crime indices (e.g., UCR, NCVS, and SRS) show that crime is disproportionately committed by men (Beirne \& Messerschmidt, 2011). Studies reveal that experts who investigate the perpetrators of sexual abuse also report that men are more likely to engage in sex offending (Landor \& Eisenchlas, 2012). Comparatively, females are viewed as nurturing and caring, and if, they commit a sexual offense, there is an underlying cause as to why. Recently, reports have emerged involving inappropriate sexual behavior between female teachers and male students, as well as female babysitters. However, those reports do not completely examine the vast sexual crimes committed by females or the complexity of these cases.

For many people, the idea of women engaging in sexual offending defies belief and is viewed as an aberration since it challenges conventional stereotypes about the roles of women as caring, nurturing, and protecting of children (Zack, Long, \& Dirk, 2018). Nevertheless, the idea that women can also be sexually predatory is gaining attention as scholars and law enforcement officers report that FSOs are more common than one would think (Stemple et al., 2017; Cortoni, Babchishin, \& Rat, 2017; Jarrett, 2017). This finding is not only evident in the U.S., but also appears to be a global problem (Tozan et al., 2019). Therefore, because little attention has been given to FSOs, this investigation examines this neglected area of research. As such, this paper is divided into three parts. Part One explores the prevalence and typologies of FSOs. Part Two provides a theoretical explanation of FSOs. Part Three addresses female sex offending as a neglected criminal justice issue. In the end, we provide a conclusion with suggestions on how to reduce female sexual offending.

\section{Prevalence and Typologies of FSOs}

Sexual abuse statistics show that children and adolescents are targeted by both men and women perpetrators. In fact, evidence suggests that when it comes to sexual crimes committed nationally, men and women commit them at $96 \%$, and $4 \%$, respectively. However, when the victims of sexual abuse are children, the numbers for males and females appear similar. Despite this, the perpetrators often use different approaches to sexually abuse children. For example, some 
studies suggest that women often sexually abuse children (primarily young boys) who are family members while in their role as caregiver. Despite this, some experts disagree that FSOs have different modus operandi. A study by Kaufman and colleagues (1995), reported that $88 \%$ of FSOs were teachers, and 23\% were babysitters. Other studies revealed that FSOs disproportionately serve as babysitters, teachers, or care givers (Burgess-Proctor et al., 2017). Comartin and colleagues (2018) reported that unlike men, women child sexual offenders are likely to be the parent of the victim, have a co-offender, and repeatedly target the same victim (Williams \& Bierie, 2015; McLeod, 2015).

According to a US Department of Justice study of 60,991 sexual assault victims, what is more alarming about women sexual offenders is that they are more likely to sexually assault victims under the age of 6 years old. The study reported that among the very young that were sexually victimized, $12 \%$ of the predators were females. For those victims aged $6-12,6 \%$ of the offenders were females. For victims who were between the ages of $12-17,3 \%$ of the offenders were females (Snyder, 2000; Bourke et al., 2014). Statistics also show that female offenders comprised less than $10 \%$ of those arrested for committing sexual crimes. More specifically, these data suggest that women represent only $1 \%$ of all adult arrests for forcible acts of rape, and $6 \%$ of all adult arrests for other sex crimes. Similarly, Sandler, \& Freeman (2009) reported that while the arrest rates for female involvement in sex crimes is nationally consistent, their conviction rates range between $1 \%$ and $6 \%$ throughout the U.S, but vary from one jurisdiction to another. Research also reveals that when it comes to the age of FSOs, juvenile arrest data finds that adolescent female offenders account for $3 \%$ of forcible rape cases, and 5\% of other violent sex offenses (Snyder \& Sickmund, 2006). Other studies find that while many FSOs are in their 20s and 30s, they are often younger when they start sexually abusing children (Bourke et al., 2014; Johansson-Love \& Fremouw, 2009).

Because of methodological weaknesses in most FSO research, experts question the accuracy of this scholarship since these studies often use small or nonrepresentative convenience samples. Thereby, making it impossible for researchers to generalize and infer from the findings (Saradjian, 2000; Tozdan et al., 2019). This is only one factor that prevents experts and scholars from assessing the total number of incidents and cases that occur each year. Moreover, researching FSOs is challenging and complicated since child sexual abuse, whether perpetrated by male or female, is often committed in private and unless the behavior is witnessed publicly or reported by someone other than the victim, the actual number of incidents are likely to go unreported since, in most cases, research finds that sex crimes are only seen by the victims and perpetrators (Wiseman, 2015).

\subsection{Efforts to Assess the Pervasiveness of FSO}

Despite these concerns, efforts are made to assess the actual number of female sexual offenses that occur. For example, Tozdan, Briken, \& Dekker (2019) reported that in the U.S., official crime data from the National Incident Based Reporting System (NIBRS), that focused on female sexual offenses committed by relatives of the victims, revealed from 1991-1996, women offenders committed an estimated 40,804 sexual crimes against children and adolescents between the ages 1 through 17. More specifically, NIBRS data revealed that 8,539 victims were younger than $6 ; 12,260$ victims were ages 6-12; and 20,005 victims were between the ages of 12-17. Moreover, the type of sexual offences ranged from "vaginal and anal penetration or attempted penetration with fingers, penis, objects, or oral sex, attempted oral sex, unwanted sexual touching or fondling" (Tozdan et al., 2019, p2). Similarly, Williams \& Bierie (2015) examined NIBRS data, but focused on 1991 through 2011 as their timeframe. They reported that $5 \%$ of more than 800,000 incidents of sexual offenses involved FSOs. However, unlike Tozdan and colleagues' analysis, William \& Bierie reported that $61.9 \%$ of the cases $(n=26,630)$ were women acting alone, and they were co-offenders in the remaining $38.1 \%(n=16,388)$ of incidents. In these cases, the majority involved a male co-offender $(n=13,986)$. This finding established that in two thirds of female sexual offending cases, they engaged in this behavior on their own. While the reported sexual offenses committed by women are shocking, child abuse experts warn that they may not reveal the total number of sexual incidents that children and adolescents experience each year since this crime is similar to other forms of assaultive violence in that they often go unreported and or underreported. As such, if these incidents are not reported to police, they are not included among the UCR or NIBRS statistics.

\subsection{A Hexamer Typology of Adult and Adolescent FSOs}

Experts argue that not every FSO is the same since they often use a different modus operandi. Research places these adult and adolescent offenders into separate categories because they typically commit sexual offenses for different reasons (Davin et al., 1999; Matthews et al., 1989). It is critical that researchers and healthcare experts who treat them recognize the different typologies of FSOs. Consequently, some experts have identified several typologies of females who engage in sexual abuse (Vandiver \& Kercher, 2004). The literature of FSOs suggests that a hexamer typology exists. The adult female typology includes: the predisposed intergenerational; teacher/lover; and co-offender. Adolescent female typology includes: the sexually curious; the sexually reactive; and repetitive abusers (Applewhite, 2005). 


\subsection{Adult Female Sexual Offenders: Predisposed intergenerational}

Adult female sex offenders who are predisposed often suffer a history of sexual abuse as children. They have experienced incest with several people that include family members and caretakers (Applewhite, 2005). They are also likely to experience continued sexual victimization as adults. They suffer mental health issues throughout their lives. Studies report these FSOs do not act in concert with others, but rather, they engage in sexual deviant behaviors on their own. Some research reveals that because of their past experiences of incest, they are likely to sexually abuse their own children and other young children who are also family members. They may become physical or sadistic with children as young as six while acting out sexual fantasies (Mathews et al., 1989).

\subsection{Teacher/lover}

Teachers often come from healthy backgrounds. They voluntarily enter a relationship with a student and view them as being on equal footage. Yet, they are undeniably in positions of power and authority since they are educators and older. Mathews and colleagues (1989) reported that these FSOs teach prepubescent and adolescent boys about sexuality. They view the sexual exchange as an act of kindness. Furthermore, studies show that teachers view these relationships as romantic and cherish the child or teenager as a true lover (Applewhite, 2005). While the victim can either be a male or female pre-or-post adolescent, in most cases, offenders fall in love with an adolescent male student. Applewhite's research finds that teachers report feelings of loneliness or abandonment and consequently they turn to students to fill a void in their lives. They fail to see the harm the illegal relationship causes the child or teenager.

\subsection{Male Coerced/Male Accompanied}

This type of offender is found in physically and sexually abusive relationships with men who desire or fantasize about bringing children into their sexual relationship. Research suggest that many of these men have already sexually abused children (Mathews et al., 1989). The women in these relationships have substance abuse histories. They are often passive and dependent on their physically and sexually dominant and controlling male counterpart. These men direct them to engage in sexual behavior with either their own children or other children who are relatives (Gannon \& Rose, 2008). Research suggests that because they fear their mate will leave or abandon them, they give into his wishes to engage in sexual offenses. Sometimes they engage in sex with the adult male and child out of fear of physical threats and punishment. Other times, they comply because of their hopelessness and powerlessness in the relationship. Research even suggests that some women continue sexually abusing children when the male is removed from the situation or is no longer a partner in the sexual abuse (Gannon \& Rose, 2008).

\subsection{Adolescent Female Sexual Offenders: Sexually Curious}

These adolescent females' sexual curiosity leads them to target young male children that they babysit. Studies reveal that these offenders are inexperienced and naïve about sex. They use children in their care to experiment and explore areas related to sex. Research also reports that these offenders are rarely sexual or physical abuse victims, but rather, they desire sexual experiences. They are not emotionally or psychologically disturbed, but rather, they are simply unaware that children are not consenting persons or peers (Applewhite, 2005).

\subsection{Sexually Reactive}

Sexually reactive offenders are female teenagers who have been the victims of sexual abuse. Those exposed to early sexual trauma or incomprehensible sexual stimuli may also experience hyper-sexuality or sexual behavior problems that could manifest into predatory behavior. Some research suggests that adolescents who suffer extreme neglect may react in a sexual way to receive self-stimulation to relieve stress (Cohu, 2017). Researchers emphasize that it is important to know that not all children who were sexually abused will become aggressive or predatory. Those who study sexually reactive adolescent offenders reveal that they recreate their own sexual victimization when they engage in sexual behavior. While many of them are emotionally disturbed, it is not severe or acute enough to render them antisocial or dysfunctional in every case (Cohu, 2017).

\subsection{Repetitive Abusers}

This type of adolescent FSOs has family histories that are characterized as chaotic and sexually abusive. After having experienced physical and sexual abuse early on, these adolescents suffer trauma, emotional instability or disturbance, mental health problems, and instability (Harris, 2010). Health experts warn that if not treated, these adolescents may become adult predisposed sexual offenders. These sexual offenders often engage in more repetitive, extensive, and severe abuse than others on a repetitive basis and are known to have many victims. Of the adolescent female offenders, this group is more difficult to treat. As this hexamer typology suggests, FSOs are diverse and motivated by different reasons. Thus, typologies are believed to assist counselors, clinicians, and justice officials (i.e., in preparing a presentence investigation report PSIR) to better treat and assess the adult and adolescent females who engage in sexual abuse (Harris, 2010). 


\section{Theoretical Explanations of FSOs}

Criminologists have paid scant attention to FSOs. In fact, criminological research disproportionately focuses on women as victims. Despite criminologists' neglect, research investigations on FSOs have largely come from sociologists, psychologists, psychiatrists, and other practitioners. Their work has contributed greatly to our understanding of sex typologies. However, these efforts lacked an analysis on the etiology of female sex offending. Experts warn that without developing a theoretical explanation specific to females, it would be difficult to clinically assess, adequately treat, or punish FSOs. The same experts often cite the absence of research in the literature since most theories of sex offending are based on male offenders. This poses a challenge for researchers since it treats FSOs as the generalized other without adequate analysis of the actual perpetrators of crime (Stathopoulos, 2014). Feminist scholars have always advocated for a gender-specific criminology that addresses the etiology of women's participation in crime (Chesney-Lind, 1998). Nevertheless, there are two types of theories that have been used to explain female sex offending: single factor and multifactor theories (Faupel, 2015; Harris, 2010).

Single factor theories rely on a narrow set of elements to explain sex offending. They are often: biological (e.g., hormones, testosterone levels, physiologically or biologically, predetermined sexual appetites/sexual preferences); behavioral (e.g., aspects of conditioning and learning); sociocultural (e.g., societal and cultural norms, structures, sexualized images of women and children); and attachment/intimacy (problems attaching lead to issues with intimacy and rejection causing sexually abusive behavior). Despite this, feminist scholars argue that the gender-relations girls and women find themselves within patriarchal societies create conditions (e.g., imbalance of power, dependency, violence) that explain their involvement in crime (Faupel, 2015; Harris, 2010). Because female sex offending is complex, some scholars find singular explanations as inadequate. As such, they prefer multifactor explanations since they integrate several reasons to explain the complexity of female sex offending.

While there are several multifactor theories that include Finklehor's preconditioning theory, Hall \& Hirchschman's quardipartite model, Ward \& Siegart's pathway model and others, we subscribe to Marshall \& Barbaree's (1990) integrated theory because it is prominently cited in the sex offender literature. It argues that sex offending is caused by multiple factors that include one's developmental experiences, biological processes, cultural norms, and psychological vulnerability. Marshall \& Barbaree argued that early childhood negative experiences such as sexual abuse, physical abuse, and neglect causes the abused child to view his/her parents or caregivers as being emotionally unreachable or absent. It also causes the abused child to see him/herself as unworthy of love or protection. As a result, the child can develop low self-esteem, poor interpersonal skills, and suffer poor coping skills. Furthermore, if there is an abusive father in the environment who displays misogynistic behavior, a male child who suffers feelings of inadequacy may grow to display dominant behavior. Their theory suggests that an abused person may use sex to meet many psychological needs that go beyond physical gratification to providing competence, self-esteem, connectivity, and achieving masculinity.

Though complex, Marshall \& Barbaree's theory has gained support from several studies including Smallbone \& Dadds' (2000) work which revealed insecure childhood attachments, especially with parents, can be linked to later coerced sexual behavior. Similarly, Knox (2014) reported that juveniles who committed a sexual offense also revealed that they had low levels of attachment to their biological fathers or father figures compared with a group of juveniles who committed nonsexual offenses. While evidence supports this approach to understanding sex offenders, critics charge that it also presents areas of concern, namely the embedded offense pathways to sex offending behavior. More specifically, they argue that there are distinct and competing pathways in the model that are concerning. For example, there is little agreement on which specific pathway causes sex offending. Consequently, critics assert that each pathway must be identified and distinguished from the other before one can say with certainty that a particular pathway leads to sexual offending. This poses an even larger question for researchers, that is, whether these pathways explain why females commit sex offending since there has not been a theory created solely to explain female sex offending. Notwithstanding, Harris (2010) argues feminist criminology holds promise since it uses pathways (which recognizes multiple factors and experiences) to explain female sex offending. She considers the powerlessness and exploitation that girls and women experience in capitalistic societies (characterized by male domination) and how it leads to their victimization. For example, when a female heads the household, she can experience feelings of isolation and stress. "Abuse, neglect, or over-discipline of a child might be the only opportunity she has to feel in control" (Harris, 2010, p. 37). Moreover, if she was sexually abused as a child, she may feel little control over her sexuality. As a result, she may sexually abuse others to obtain power and control.

Despite criminology's neglect to focus on FSOs, its current use of the life-course theory holds tremendous promise since it combines multifactorial explanations to explain gender related crimes (Beirne \& Messerschmidts, 2011). Life-course theory suggests researchers consider examining the lived experiences (e.g., behavioral, societal, cultural, structural) of offenders to fully understand the different pathways or life stories that invariably explains their behavior. 
More specifically, several scholars reported that when studying sex offenders and the perpetrators of other forms of assaultive violence, they found success within the context of focusing on an offenders' entire life experiences since it revealed critical periods and events that chronicled important processes of their violent and nonviolent development. Some of which, were critical turning points for future offenders (Chesney-Lind \& Sheldon, 2004). Life-course theory compliments feminist theory because it leads to an examination of the experienced exploitation and oppression of females that can explain their involvement in crime.

Gannon and colleagues (2008) and Gannon, Rose, \& Ward (2012) studied female sex offending in the UK by relying on the grounded theory approach. They used the Descriptive Model of Female Sexual Offending which enabled them to elucidate the role of affective, cognitive, behavioral, and contextual factors associated with sex abusers to understand why women engaged in sex offending. The study found that women experienced multiple forms of abuse and each woman's adult lifestyle reflected early emerging social, affective, and psychological vulnerability factors that later developed into risk factors. This study sets a threshold for future theoretical developments which can be empirically validated and used to identify and manage female sex offenders.

\section{Female Sexual Offending: A Neglected Criminal Justice Issue}

When sex crimes are reported, the criminal justice system is charged with investigating them (Gaines \& Miller, 2008). Therefore, the justice system's response is naturally reactionary. For this reason, critics believe its response to female sex offenses will never adequately address this silent and hidden crime. While some view the justice system's reaction as reasonable, critics charge that even when FSOs are arrested, the system treats them differently compared with male sexual offenders. Embry \& Lyons (2012) reported that sentencing disparities exist between female and male sexual offenders. They revealed that FSOs receive substantially less prison time compared with men who engage in the same behavior. More specifically, they reported that men received prison sentences that were between $6 \%$ and $31 \%$ longer than women. While shocking, this finding may not be an exception, but rather, studies reveal that it's the rule. In fact, as early as the 1980s, research on FSOs revealed that in those few cases where women were criminally charged with sexually abusing children, (though the children were removed), the justice system allowed them to plea to a lesser crime. When convicted, they typically received a stay of imposition or execution and were given probation with treatment as a condition of release (Mathews et al., 1989). More recently, studies examining the gender of sex offenders and their punishment consistently report FSOs receive lenient sentences from the justice system (Koons-Witt, 2002; Jeffries et al., 2003; Farnsworth \& Teske, 1995).

While curious about the disparate treatment given to some sexual offenders, scholars have explored several explanations regarding why sentencing disparities favor women offenders. In doing so, they researched patriarchy, chivalry, and the evil woman hypotheses (Koons-Witt, 2002; Rodriguez et al., 2006). Most research supports that women offenders receive a different brand of justice from the system because it feels a need to protect women including those who sexually abuse children and adolescents (Embry \& Lyons, 2012). Consequently, the justice system holds women to a lesser degree of blameworthiness than it does men, even when they engage in similar sexual offenses (Embry \& Lyons, 2012). Moreover, other research also supports that the chivalry hypothesis explains why women are more likely to receive a lesser punishment. Research shows the sentencing disparity is more likely when accused women conform to stereotypical roles such as having children or providing childcare (Koon-Witt, 2002). Studies find when women lack stereotypical requisites, they are likely to receive a severe sentence since chivalry is withheld (Koons-Witts, 2002; Griffin \& Wooldredge, 2006). Other studies suggest judges are likely to grant women a reduced sentence when they consider mitigating and extralegal factors (i.e., prior record, and presentence investigation report) for gender differences. Jeffries and colleagues (2003) reported that since men are more likely to have a prior record compared with their female counterparts, women are likely to be diverted from a lengthy prison sentence.

Despite its reactionary posture, the justice system uses several strategies to protect communities from sex offenders. Thus, it requires police to inform residents when sex offenders have been released and returned to the community. To that end, Megan's Law serves as a national criminal justice response to sexual predators that is used in each state and by the federal government to alert community residents about the presence of sex offenders (Gaines \& Miller, 2008). Furthermore, the justice system monitors registered sex offenders by requiring them to be supervised by a parole officer (PO) with the understanding that their status can be revoked (and they will be returned to prison), if they fail to register and stipulate to conditions of release which are often six-fold. They include: (1) not having any contact with children under age 16; (2) receiving permission from their PO to change address; (3) not owning toys that can be used to lure children; (4) staying a proscribed distance from areas where children frequent (e.g., schools, playgrounds, and parks); (5) not working at or participating in activities that include children; and (6) continue receiving treatment for their sexual problems (Gaines \& Miller, 2008). Megan's Law also requires sex offenders who attend college to disclose their status to the university. More importantly, sex offenders are required to contact and inform law enforcement and register as a sex offender when they relocate to a new area (Gaines \& Miller, 2008). Despite this national effort, Megan's Law has proven unsuccessful since 
some registered sex offenders recidivate.

Because the national sexual registration effort has failed to deter offenders, several states have responded by getting tougher on sex offenders. For example, New York and Pennsylvania require that all rapists (minor and adult) register as sex offenders. This includes pimps and child pornographers. In Massachusetts, the law requires that all Level III sex offenders (i.e., those deemed by the court to be at a high risk of reoffending) provide the addresses of their partners and family as part of their registration process. In 2005, Florida passed the Jessica Lunsford Act which is considered the toughest sex offender law in the nation. Under the Act, if one is convicted of molesting a child under the age of 12, the perpetrator will receive a mandatory sentence for at least 25 years and must wear a global tracking device for the rest of his or her life when released from prison. While Florida's approach is tough on sexual offenders who target very young victims, another strategy used to protect community residents from sexual predatory or habitual sex offenders is referred to as civil commitments. They are designed to keep habitual sex offenders out of the community indefinitely. While controversial, they are a form of involuntary confinement based on what an offender may do in the future. Therefore, if it is determined that a sex offender is still likely to pose a threat to the community after serving a prison sentence, he or she can receive a civil commitment to be served in either a psychiatric hospital or health care facility. Because it is controversial, the practice was challenged in Kansas v. Hendricks (1997). In Hendricks, the U.S. Supreme Court held that Kansas' Sexually Violent Predator Act did not violate the double jeopardy or ex post facto clauses of the Constitution alleged by Hendricks, an inmate with a history of sexually molesting children. In this case, the Court ruled that Kansas' use of a civil commitment on a person who, due to a "mental abnormality" or a "personality disorder," is likely to engage in "predatory acts of sexual violence" was constitutional. Currently, an estimated 22 states allow habitual sex offenders to be civilly committed after serving a prison sentence for their original sexual offense.

\section{Conclusion}

Our research disproportionately relied on small samples due in part to the number of FSOs in the population and because many have not been caught or convicted. Despite this, studies and official reports suggest that female sex offending is on the rise. Therefore, further research should be conducted on this special offending population (Shields \& Cochran, 2019; McLeod \& Craft, 2015; Stemple et al., 2017). Based upon our findings, we conclude that efforts be made to produce gender parity in understanding the etiology, punishment, treatment, and public health issues related to female sex offending. As such, our suggestions are five-fold.

First, there is an increased need to know more about reported and unreported FSOs. While we currently rely on community-notifications, public registries, global tracking devices, and civil commitments (Rogers \& Ferguson, 2011), researchers, social workers, policymakers, and justice officials should monitor indicators of sexual offenses by females to better understand the factors influencing patterns in the data, why offenses occur, as well as sentencing policy decision-making and practices designed to prevent sex offending (Shield \& Cochran, 2019). Ideally, what is needed is a national clearinghouse that collects and stores accurate data on male and female sexual offenders. This cannot occur without more citizens reporting their sexual victimization, arrests made, and increasing inclusivity from local law enforcement from across the nation.

Second, agencies involved in making policies regarding FSOs should engage in a multidisciplinary collaboration which allows agencies to form partnerships and develop policies aimed at managing and controlling FSOs, assess the victim impact of those policies, and seek input from each partner as to the most effective manner(s) to hold each FSO accountable while providing support and safety for victims. Similarly, Gostin (2000) contends this combined effort will apply multiple strategies that address all aspects of female sex abuse.

Third, Embry \& Lyons (2012) revealed male sex offenders received sentences between 6\% and 31\% longer than their female counterparts. Similarly, Shields \& Cochran (2019) reported that after examining 15 years of data on all felony sex offenders sentenced in a single state, they found that court decisions are influenced by non-evidentiary factors such as gendered views of sex offenders that result in a gender gap in punishment received by sex offenders. Consequently, FSOs are treated differently compared with their counterparts. In fact, in the few cases where they are sentenced, they are often allowed to remain in the community (Shields \& Cochran, 2019). While studies indicate gender disparity between female and male sex offenders due to FSOs receiving lighter sentences (i.e., the female has traditionally been viewed as a nurturer, not a sex offender), just as the justice system punishes male sex offenders, it should equally mete out punishment to FSOs. This is not to suggest that the justice system get even with females by giving them harsh punishments (e.g., extended periods of incarceration) since it may believe that similar punishment is not needed to deter female offenders. In fact, some evidence suggests that male sex offenders are at a higher risk of recidivating and require institutionalization in order to receive needed intensive treatment. This perception is usually not the case for females. However, we agree with findings by Meloy and colleagues (2013) and Shields \& Cochran (2019) that suggest future policy research should examine what is appropriate and effective on current sex offenders. This can be achieved in part 
by presentence investigation reports (PSIR). Moreover, decision makers in general, and court actors in particular, should consider whether there are any anti-therapeutic consequences to their approaches. In the end, justice policies should provide equal sentencing for all sex offenders despite their heterogeneity, especially if sentencing policies are designed to enhance public safety and not give a false sense of security. Moreover, if the justice system does not mete out appropriate punishment, it risks failing to send any deterrent message to FSOs.

Fourth, Vess (2011), asserts gender-specific assessments should be conducted to discover factors that contribute to female sex offending. Justice policymakers must recognize that FSOs exist and must be provided proper gender and case specific treatment in correctional settings. Researchers and scholars must continue to engage the issue of female sex offending at conferences and in discussions with colleagues. Given the large, and at times, disproportionate representation of African American and Latino women in correctional settings, additional research should be conducted regarding issues of race, cultural, and socioeconomic context of FSOs.

Fifth, as a matter of public policy, criminal justice personnel along with victim advocacy groups should further educate communities by providing them with information on how to protect themselves and their families from being victims of FSOs. This information should serve a threefold purpose. First, it will help individuals recognize the importance and need to manage sex offenders in the community. Second, realize there may be more sex offenders living in the community who have not been caught. Third, identify and verbalize their fears/perceptions about FSOs. Since the general public is influenced by misinformation and stereotypes such as males being the only gender capable of committing sex crimes, a paradigm shift is needed so that policy can be driven by empirical data, rather than popular misconception. This will only occur when justice officials collect factual and accurate data on FSOs and share the realities about sexual offending with the general public. The justice system must also punish all perpetrators of sexual offenses without deference to gender.

\section{References}

Applewhite, M. (2005). Typologies of adult and adolescent female sexual offenders. A program and service of the national catholic risk retention group, Inc. Retrieved from https//www.virtueonlone.org/virtus/free-article cfm? Free-articles-id-881

Beirne, P., \& Messerschmidt, J. W. (2011). Criminology: A sociological approach (5th ed.). New York, NY: Oxford University Press.

Bourke, A., Doherty, S., McBride, O., Morgan, K., \& McGee, H. (2014). Female perpetrators of child sexual abuse: Characteristics of the offender and victim. Psychology, Crime \& Law, 20, 769-780. https://doi.org/10.1080/1068316X.2013.860456

Burgess-Proctor, Comartin, E. B. A., \& Kubiak, S. P. (2017). Comparing female and male-perpetrated child sexual abuse: A mixed methods approach. Journal of Child Sexual Abuse, 26(6), 657-676. https://doi.org/10.1080/10538712.2017.1336504

Chesney-Lind, M. (1998). Girls' crime and woman's place: Toward a feminist model of female delinquency. Crime and Delinquency, 35, 5-30. https://doi.org/10.1177/0011128789035001002

Chesney-Lind, M., \& Shelden, R. G. (2004). Girls, delinquency, and juvenile justice (3rd ed.). Belmont, CA: Wadsworth/Thomson.

Cohu, M. (2017). Parenting children or youth who are sexually reactive. Retrieved from https://www.nacac.org/resource/parenting-children-or-youth-who-are-sexually-reactive/

Comartin, E. B., Burgess-Proctor, A., Kubiak, S., Bender, K. A., \& Kernsmith, P. (2018). Comparing women's and men's sexual offending using a statewide incarcerated sample: A two-study design. Journal of Interpersonal Violence, 1-24. https://doi.org/10.1177/0886260518772110

Cortoni, F., Babchishin, K. M., \& Rat, C. (2017). The proportion of sexual offenders who are female is higher than thought: A meta-analysis. Criminal Justice and Behavior, 44(2), 145-162. https://doi.org/10.1177/0093854816658923

Davin, P., Hislop, J., \& Dunbar, T. (1999). Female sexual abusers: Three views. Brandon, VT: The Safer Society Press.

Embry, R., \& Lyons, P. (2012). Sex-based sentencing: Sentencing discrepancies between male and female sex offenders. Feminist Criminology, 7(2), 146-162. https://doi.org/10.1177/1557085111430214

Farnsworth, M., \& Teske, R. H. (1995). Gender differences in filling court processing: Testing three hypotheses of disparity. Women and Criminal Justice, 6(23), 23-44. https://doi.org/10.1300/J012v06n02_02

Faupel, S. (2015). Etiology of adult sexual offending. SOMAPI: Research Brief. Office of Sex Offender Sentencing, 
Monitoring, Apprehending, Registering and Tracking. Office of Justice Programs: U.S. Department of Justice, Washington, D.C.

Gaines, L. K., \& Miller, R. L. (2008). Criminal justice in action: The core (4th ed.). Belmont, CA: Thomson/Wadsworth.

Gannon, T. A., \& Rose, M. R., \& Ward, T. (2012). A descriptive offence process model of female sexual offending. In Schwartz, B. (Ed.), The sex offender (volume 7) (pp 16.1-16.19). Kingston, NJ: Civic Research.

Gannon, T. A., \& Rose, M. R. (2008). Female child sexual offenders: Toward integration and practice. Aggression and Violent Behavior, 13(6), 442-461. https://doi.org/10.1016/j.avb.2008.07.002

Gostin, L. O. (2000). Public health law: Power, duty, restraint. Berkeley: University of California Press.

Griffin, T., \& Wooldridge, J. (2006). Sex-based disparities in felony dispositions before versus after sentencing reform in Ohio. Criminology, 44(4), 893-923. https://doi.org/10.1111/j.1745-9125.2006.00067.x

Harris, D. A. (2010). Theories of female sexual offending. In Gannon, T. A., \& Cortoni, F. (Eds.), Female sexual offenders: theory, assessment, and treatment (pp. 31-52). Hoboken, NJ: Wiley-Blackwell. https://doi.org/10.1002/9780470666715.ch3

Jarrett, C. (2017). Sexual offending by women is surprisingly common, claims US study. Retrieved from https://www.digest.bps.org.uk

Jeffries, S., Fletcher, G. J., \& Newbold, G. (2003). Pathways to sex-based differentiation in criminal court sentencing. Criminology, 41(2), 329-353. https://doi.org/10.1111/j.1745-9125.2003.tb00990.x

Johansson-Love, J., \& Fremouw, W. (2009). Female sex offenders: A controlled comparison of offender and victim/crime characteristics. Journal of Family Violence, 24(6), 367-376. https://doi.org/10.1007/s10896-009-9236-5

Kaufman, K., Wallace, A., Johnson, C., \& Reeder, M. (1995). Comparing male and female perpetrators modus operandi: Victim's reports of sexual abuse. Journal of Interpersonal Violence, 10(3), 322-333. https://doi.org/10.1177/088626095010003006

Knox, L. A. (2014). Attachment and adolescent offending: An examination of the links between sexually abusive behavior and the level of attachment to parents and peers. Dissertations and Theses. Portland, OR: Portland State University.

Koons-Witt, B. A. (2002). The effect of gender on the decision to incarcerate before and after the introduction of sentencing guidelines. Criminology, 4O(2), 297-327. https://doi.org/10.1111/j.1745-9125.2002.tb00958.x

Landor, R., \& Eisenchlas, S. (2012). Coming clean on duty of care: Australian print media's representation of male versus female sex offenders in institutional context. Sexuality \& Culture, 16(4), 486-502. https://doi.org/10.1007/s12119-012-9134-5

Marshall, W. L., \& Barbaree, H. E. (1990). An integrated theory of the etiology of sexual offending. In W.L. Marshall, D.R. Laws, and H.E. Barbee (eds), Handbook of sexual assault: Issues, theories, and treatment of the offender (pp. 257-275). New York, NY: Plenum. https://doi.org/10.1007/978-1-4899-0915-2_15

Mathews, R., Matthews, J. K., \& Speltz, K. (1989). Female sexual offenders: An exploratory study. Brandon, VT: Safer Society Press.

McLeod, D. A. (2015). Female offenders in child sexual abuse cases: A national picture. Journal of Child Sexual Abuse, 24(1), 97-114. https://doi.org/10.1080/10538712.2015.978925

McLeod, D. A., \& Craft, M. (2015). Female sexual offenders in child sexual abuse cases: National trends, associated with child protective services system entry, exit, utilization, and socioeconomic. Journal of Public Child Welfare, 9(4), 399-416. https://doi.org/10.1080/15548732.2015.1064849

Meloy, M., Curtis, K., \& Boatwright, J. (2013) The sponsors of sex offender bills speak up: policy makers' perceptions of sex offenders, sex crimes, and sex offender legislation. Criminal Justice Behavior, 40(4), 438-452. https://doi.org/10.1177/0093854812455740

Rodriguez, S. F., Curry, T. R., \& Lee, G. (2006). Gender differences in criminal sentencing: Do effects vary across violent, property, and drug offenses? Social Science Quarterly, 87(2), 318-339. https://doi.org/10.1111/j.1540-6237.2006.00383.x

Rogers, D. L., \& Ferguson, C. J. (2011). Punishment and rehabilitation attitudes toward sex offenders versus nonsexual offenders. Journal of Aggression, Maltreatment, \& Trauma, 20(4), 395-414. 
https://doi.org/10.1080/10926771.2011.570287

Sandler, J. C., \& Freeman, N. J. (2009). Female sex offender recidivism: A large-scale empirical analysis. Annuals of Sex Research, 21(4), 455-473. https://doi.org/10.1177/1079063209347898

Saradjian, J. (2010). Understanding the prevalence of female-perpetrated sexual abuse and the impact of that abuse on victims. In T. Gannon \& F. Cortoni (Eds.), Female sexual offenders: Theory, assessment, and treatment (pp. 9-30). Malden, MA: Wiley-Blackwell. https://doi.org/10.1002/9780470666715.ch2

Shields, R. T., \& Cochran, J. C. (2019). The gender gap in sex offender punishment. Journal of Quantitative Criminology. https://doi.org/10.1007/s10940-019-09416-X

Smallbone, S.W., \& Dadds. M.R. (2000). Attachment and coercive sexual behavior. Sexual Abuse Journal of Research and Treatment, 12(1), 3-15. https://doi.org/10.1177/107906320001200102

Snyder, H. (2000). Sexual assault of young children as reported to law enforcement: Victim, incident, and offender characteristics. Retrieved December, 2002, American Bureau of Justice Statistics Clearinghouse. Retrieved from http://www.ojp.usdoj.gov/bjs/312-314

Snyder, H., \& Sickmund, M. (2006). Juvenile offenders and victims: 2006 national report. Washington, DC: U.S. Department of Justice, Office of Justice Programs, Office of Juvenile Justice and Delinquency Prevention.

Stathopoulos, M. (2014). The exception that proves the rule: Female sex offending and the gendered nature of sexual violence. Australian Center for the Study of Sexual Assaults (ACSSA) Research Summary, Australian Institute of Family Studies.

Stemple, L., Flores, A., \& Meyer, I. H. (2017). Sexual victimization perpetrated by women: Federal data reveal surprising prevalence. Aggression \& Violent Behavior, 33, 302-311. https://doi.org/10.1016/j.avb.2016.09.007

Tozdan, S., Briken, P., \& Dekker, A. (2019). Uncovering female child sexual offenders-needs and challenges for practice and research. Journal of Clinical Medicine, 8(3), 401-411. https://doi.org/10.3390/jcm8030401

Vandiver, D., \& Kercher, G. (2004). Offender and victim characteristics of registered female sexual offenders in Texas: A proposed typology of female sexual offenders. Sexual Abuse: A Journal of Research and Treatment, 16(2), 121-137. https://doi.org/10.1177/107906320401600203

Vess, J. (2011). Risk assessment with female sex offenders: Can women meet the criteria of community protection laws? Journal of Sexual Aggression, 17(1), 34-45. https://doi.org/10.1080/13552600.2010.528844

Williams, K., \& Bierie, D. (2015). An incident-based comparison of female male sexual offenders. Sexual Abuse: A Journal of Research Treat, 27(3), 235-257. https://doi.org/10.1177/1079063214544333

Wiseman, J. (2015). Incidence and prevalence of sexual offending (Part I). SOMAPI Research Brief. Office of Justice Programs, U.S. Department of Justice.

Zack, E., Lang, J. T., \& Dirks, D. (2018). "It must be great being a female pedophile!”: The nature of public perceptions about female teacher sex offenders. Crime Media Culture, 14(1), 61-79. https://doi.org/10.1177/1741659016674044

\section{Cases Cited}

Jessica Lunsford Act, (H.R. 1505 of the 109th Congress).

Kansas v. Hendricks, 521 U.S. 346

Megan's Law, Penal Code $\$ 290.46$

\section{Copyrights}

Copyright for this article is retained by the author(s), with first publication rights granted to the journal.

This is an open-access article distributed under the terms and conditions of the Creative Commons Attribution license which permits unrestricted use, distribution, and reproduction in any medium, provided the original work is properly cited. 